\title{
Pancreatic cancer stem cell proliferation is strongly inhibited by diethyldithiocarbamate- copper complex loaded into hyaluronic acid decorated liposomes
}

Alessandro Marengo ${ }^{1, \S}$, Stefania Forciniti ${ }^{2, \S}$, Ilaria Dando ${ }^{2}$, Elisa Dalla Pozza ${ }^{2}$, Barbara Stella ${ }^{1}$, Nicolas Tsapis ${ }^{3}$, Najet Yagoubi ${ }^{4}$, Giuseppina Fanelli ${ }^{5}$, Elias Fattal ${ }^{3}$, Christopher Heeschen ${ }^{6}$, Marta Palmieri $^{2, *}$, Silvia Arpicco ${ }^{1, *}$

${ }^{1}$ Department of Drug Science and Technology, University of Torino, Italy

${ }^{2}$ Department of Neuroscience, Biomedicine and Movement, Biochemistry Section, University of Verona, Verona, Italy

${ }^{3}$ Institut Galien Paris-Sud, CNRS, Université Paris-Sud, Université Paris-Saclay, 92296 ChâtenayMalabry, France

${ }^{4}$ EA 401, Matériaux et Santé, Université Paris-Sud, Université Paris-Saclay, 92296 ChâtenayMalabry, France

${ }^{5}$ Department of Ecological and Biological Sciences, University of Tuscia, Viterbo, Italy

${ }^{6}$ Stem Cells in Cancer \& Ageing, Barts Cancer Institute, Queen Mary University of London, London, UK

${ }^{\S}$ Equal contribution

*Co-corresponding authors:

Silvia Arpicco

Department of Drug Science and Technology, University of Torino

Via Giuria 9, 10125 Torino, Italy

Tel: +39.011 .6706668$

E-mail address: silvia.arpicco@unito.it

Marta Palmieri

Department of Neuroscience, Biomedicine and Movement, Biochemistry Section, University of Verona

Strada Le Grazie 8, 37134 Verona, Italy

Tel: +39.045 .8027169$

Fax: +39.045 .8027170$

E-mail address: marta.palmieri@univr.it 


\begin{abstract}
Background: Pancreatic cancer stem cells (CSCs) are responsible for resistance to standard therapy, metastatic potential, and disease relapse following treatments. The current therapy for pancreatic ductal adenocarcinoma (PDAC) preferentially targets the more differentiated cancer cell population, leaving CSCs as a cell source for tumor mass formation and recurrence. For this reason, there is an urgent need to improve current therapies and develop novel CSC-targeted therapeutic approaches. Methods: Hyaluronic acid (HA) decorated liposomes, containing diethyldithiocarbamate-copper $\left(\mathrm{Cu}(\mathrm{DDC})_{2}\right)$, able to target the specific CSC marker CD44 receptor were prepared by ion gradient technique and fully characterized. Their antiproliferative effect was evaluated on pancreatic CSCs derived from PDAC cell lines or patients. To clarify the mechanism of action of $\mathrm{Cu}(\mathrm{DDC})_{2}$ liposomes, ROS level neutralization assay in the presence of $\mathrm{N}$-acetyl-L-cysteine was performed.

Results: Liposomes showed high encapsulation efficiency and Cryo-TEM analysis revealed the presence of $\mathrm{Cu}(\mathrm{DDC})_{2}$ crystals in the aqueous core of liposomes. In vitro test on pancreatic CSCs derived from PDAC cell lines or patients showed high ROS mediated anticancer activity of HA decorated liposomes. The sphere formation capability of CSCs obtained from patients was drastically reduced by liposomal formulations containing $\mathrm{Cu}(\mathrm{DDC})_{2}$.

Conclusions: The obtained results show that the encapsulation of $\mathrm{Cu}(\mathrm{DDC})_{2}$ complex in $\mathrm{HA}$ decorated liposomes strongly increases its anti-proliferative activity on pancreatic CSCs.

General significance: This paper describes for the first time the use of HA decorated liposomes containing $\mathrm{Cu}(\mathrm{DDC})_{2}$ against pancreatic CSCs and opens the way to the development of nanomedicine based CSC-targeted therapeutic approaches.
\end{abstract}

Keywords: liposomes; hyaluronic acid; diethyldithiocarbamate/copper complex; CD44; pancreatic cancer stem cells; PDAC patient-derived cells. 


\section{Introduction}

Pancreatic ductal adenocarcinoma (PDAC) is a highly lethal disease that is frequently diagnosed at a late stage and represents the fourth leading cause of cancer-related deaths in the modern world with a five-year survival rate around $5-7 \%[1,2]$. In the clinic, the present therapies rarely reduce tumor size and counteract tumor reappearance, thus rendering the identification of new therapeutic strategies necessary.

A growing body of evidence suggests that PDAC initiation, growth, metastasis and resistance to therapy are driven by a small population of cells, called cancer stem cells (CSCs) or tumor initiating cells [3-5]. Pancreatic CSCs were identified in 2007 by Li et al [3], who showed that pancreatic cancer cells with the $\mathrm{CD} 44^{+} / \mathrm{CD} 24^{+} / \mathrm{ESA}^{+}$phenotype $(0.2-0.8 \%$ of all pancreatic cancer cells) possessed a 100-fold increased tumorigenic potential compared with marker negative cancer cells and just a small fraction of $\mathrm{CD} 44^{+} / \mathrm{CD} 24^{+} / \mathrm{ESA}^{+}$cells was sufficient to give rise to tumors histologically indistinguishable from the primary human tumor. After this discovery, great efforts have been made to understand the CSC biology in terms of origin and propagation, and their role in cancer progression and metastasis promotion. CSC population shows specific features, including the ability to self-renew, to produce a more differentiated progeny, to grow in independent anchorage conditions, and to resist to standard chemotherapy engendering disease relapse following treatment $[4,6]$. In the context of chemoresistance and recurrence, a major impact on tumor progression can derive from the use of treatments directed against not only differentiated cells, that represent the bulk of the tumor, but also CSCs [7]. Thus, in order to develop CSC-targeted therapies, it is important to take advantage of CSC specific features, that in part have already been identified, and of in vitro cell cultures and patient-derived xenograft models $[8,9]$ that represent the tumor heterogeneity of PDAC. For instance, a frequent strategy used in this field has been the targeting of CD44-expressing CSCs with its specific ligand, hyaluronic acid (HA) [10, 11].

The anti-alcoholism drug disulfiram (DSF, Antabuse ${ }^{\circledR}$ ) has been shown to act as antitumoral drug [12-21] and represents a possible candidate as an anti-CSC agent in breast cancer and glioblastoma $[22,23]$. The anticancer activity of DSF has not yet been fully elucidated. Indeed, several mechanisms have been proposed, such as the inhibition of aldehyde dehydrogenase, proteasome, NF-кB, DNA methyltransferase, and multidrug resistance p-glycoprotein activities [13, 23-27]. Furthermore, when used in combination with copper, DSF becomes a strong inducer of radical oxygen species (ROS) [27-30]. Despite its powerful anticancer activity, the development of DSFbased cancer therapy has been hampered by its poor solubility in biological fluid and instability in gastric juice and bloodstream [31]. To overcome these limitations, the development of drug delivery systems is crucial in order to protect DSF from degradation and increase drug concentration in 
tumor site [32]. Moreover, the encapsulation of DSF into nanoparticles renders it suitable for intravenous administration. One of the most known drug delivery system is liposomes, which, because of their structure, can encapsulate a wide range of molecules with hydrophilic, amphiphilic, or lipophilic characteristics. In addition, the phospholipidic framework ensures complete biocompatibility [33]. Along the years, the research in liposome field has been gradually oriented towards the development of systems capable of specifically recognizing the target cells [34]. This strategy, known as active targeting, involves the use of a targeting agent able to "drive" the nanosystem directly on the target cells by recognition of specific molecules overexpressed on cell surface. According to this strategy, different liposomes decorated with antibodies, peptides, small molecules, or aptamers have been developed and have shown a significant improvement in tumor drug accumulation [35-38].

In this work, we designed liposomes containing DSF or diethyldithiocarbamate-copper complex $\mathrm{Cu}(\mathrm{DDC})_{2}$ in order to obtain a nanotechnology platform able to selectively target and destroy pancreatic CSCs. This study is basically divided in two parts. The first concerns the preparation and characterization of liposomal formulations containing DSF and $\mathrm{Cu}(\mathrm{DDC})_{2}$ either plain or targeted, thus selective for pancreatic CSCs. For the active targeting strategy, HA was chosen as targeting agent because pancreatic cancer cell lines, such as Panc1 cells, and CSCs have been shown to display an over-expression of its receptor, CD44 [39]. Moreover, HA is a biodegradable, non immunogenic and non toxic polymer, features that make it a good candidate as a targeting agent $[40,41]$. In order to obtain liposomes decorated with HA, conjugates between the phospholipid 1,2dipalmitoyl-sn-glycero-3-phosphoethanolamine (DPPE) and HA were synthesized and incorporated in the liposomal preparations. HA of low molecular weight (MW) (4,800 and 17,000 Da) were chosen as targeting agents on the basis of our previous work that demonstrated a strong affinity of the oligomers towards CD44 positive pancreatic tumor cells $[42,43]$. The second part of the study concerns the in vitro evaluation of the effect of DSF and $\mathrm{Cu}(\mathrm{DDC})_{2}$ liposome formulations on proliferation of CSCs derived from PDAC cell lines or patients and the analysis of ROS to define the differential activity of the formulations on parental cells and CSCs.

\section{Material and methods}

\subsection{Materials and instruments}

Sodium hyaluronate of MW 4,800 ( $\left.\mathrm{HA}_{4800}\right)$ and 17,000 ( $\left.\mathrm{HA}_{17000}\right)$ Da were purchased from Lifecore Biomedical (Chaska, MN). All the phospholipids were provided by Avanti Polar-Lipids distributed 
by Spectra 2000 (Rome, Italy). Solvents, N-acetyl-L-cysteine (NAC), diacetylated 2',7'dichlorofluorescein (DCF-DA) probe and all the other chemicals were obtained from SigmaAldrich (Milan, Italy).

HPLC analyses were carried out using a Merck Hitachi HPLC System (Milan, Italy). The analytical column was a Symmetry C18 column, 5 m (Merck) equipped with a C18 column guard (Merck Hitachi HPLC) system. Spectrophotometric analyses were performed using Beckman Coulter DU 730 UV-vis spectrophotometer. Mass spectrometry analyses (MS) were carried out using electrospray ionization (ESI) or by atmospheric pressure chemical ionization (APCI), in positive ion mode, on a Micromass ZQ spectrometer (Waters). The ${ }^{1} \mathrm{H}$ nuclear magnetic resonance (NMR) spectra were recorded on a Bruker 300 Ultrashield instrument (Karlsruhe, Germany) in a mixture of $\mathrm{D}_{2} \mathrm{O}, \mathrm{CD}_{3} \mathrm{OD}, \mathrm{CF}_{3} \mathrm{CO}_{2} \mathrm{D}$ in a volume ratio of $6: 3: 1$ at room temperature, with $\mathrm{Me}_{4} \mathrm{Si}$ (TMS) as internal standard. Differential scanning calorimetry (DSC) was performed using a DSC Q1000 (TA Instruments). CryoTEM was performed at I2BC (Gif-sur-Yvette, France) using a JEOL JEM-1400 operating at $120 \mathrm{kV}$. Images were recorded on a US1000XP camera (Gatan Inc, CA) with a $-4.2 \mu \mathrm{m}$ defocus. The reactions were monitored by thin-layer chromatography (TLC) on F245 silica gel precoated sheets (Merck).

\subsection{Synthesis and characterization of hyaluronic acid-phospholipid conjugates}

HA-DPPE conjugates were prepared using the method described by Arpicco et al [42]. A minor modification was introduced in the purification process: to completely eliminate the unreacted phospholipid still present in the conjugate after dialysis, extraction process with dichloromethane was performed. In this way, the unreacted DPPE was solubilised in the organic phase and thus separated from the conjugate. The aqueous phase was analyzed by TLC (chloroform/methanol $70: 30 \mathrm{v} / \mathrm{v}$ ) to monitor the disappearance of free DPPE from the conjugate and the extraction with dichloromethane was repeated until complete removal of the free phospholipid. The purified compounds were freeze-dried, and the yield was $30 \%$ for $\mathrm{HA}_{4800}-\mathrm{DPPE}$ conjugate and $60 \%$ for $\mathrm{HA}_{17000}$-DPPEconjugate. ${ }^{1} \mathrm{H} \mathrm{NMR}\left(\mathrm{D}_{2} \mathrm{O}, \mathrm{CD}_{3} \mathrm{OD}, \mathrm{CF}_{3} \mathrm{CO}_{2} \mathrm{D}\right.$ in a volume ratio of $\left.6: 3: 1,300 \mathrm{MHz}\right)$ : d $0.9\left(6 \mathrm{H}\right.$, terminal $\mathrm{CH}_{3}$ of DPPE), $1.3\left(56 \mathrm{H}\right.$, methylene protons of DPPE), $1.5\left(4 \mathrm{H}, \mathrm{NHCH}_{2} \mathrm{CH}_{2}\right)$, $2.0\left(\mathrm{Nac}-\mathrm{CH}_{3}\right), 3.3-4.0$ (sugar ring protons), 4.4-4.6 (sugar ring protons).

\subsection{Preparation of DDC/metal complexes}


DDC/metal complexes were synthesized by adding dropwise MilliQ ${ }^{\circledR}$ water solution of $\mathrm{CuCl}_{2} 2 \mathrm{H}_{2} \mathrm{O}$ (75.53 mg, $0.443 \mathrm{mmol} ; \mathrm{Cu}(\mathrm{DDC})_{2}$ ) or $\mathrm{FeCl}_{3} 6 \mathrm{H}_{2} \mathrm{O}$ (119.74 mg, $0.443 \mathrm{mmol}$; Fe(DDC) $)$ or $\mathrm{ZnSO}_{4}$ $\mathrm{H}_{2} \mathrm{O}\left(79.50 \mathrm{mg}, 0.443 \mathrm{mmol} ; \mathrm{Zn}(\mathrm{DDC})_{2}\right)$ to $\mathrm{MilliQ}^{\circledR}$ water solution of DSF active metabolite sodium diethyldithiocarbamate trihydrate (DDC, $100 \mathrm{mg}, 0.443 \mathrm{mmol}$ ). The reaction was stirred at room temperature for about 10 minutes until the formation of precipitate, which indicates the occurred complexation. The solution was then filtered and the resulting precipitate was washed three times with MilliQ ${ }^{\circledR}$ water and dried under vacuum. The formation of the DDC/metal complexes was assessed by MS. $\mathrm{Cu}(\mathrm{DDC})_{2}$ : $\left(\mathrm{C}_{10} \mathrm{H}_{20} \mathrm{CuN}_{2} \mathrm{~S}_{4}\right)$ calc: 358.98 , found: 359.13 [M] $]^{+}$, $\mathrm{Fe}(\mathrm{DDC})_{2}$ : $\left(\mathrm{C}_{10} \mathrm{H}_{20} \mathrm{FeN}_{2} \mathrm{~S}_{4}\right)$ calc: 351.99 , found: $352.15[\mathrm{M}]^{+}, \mathrm{Zn}(\mathrm{DDC})_{2}$ : $\left(\mathrm{C}_{10} \mathrm{H}_{20} \mathrm{ZnN}_{2} \mathrm{~S}_{4}\right)$ calc: 359.98, found: $360.14[\mathrm{M}]^{+}$.

\subsection{Preparation of liposomes}

\subsubsection{DSF containing liposomes}

DSF containing liposomes (LipoDSF-5\%PEG) were prepared using the thin lipid film-hydration method mixing together 1,2-distearoil-sn-glycero-3-phosphocoline (DSPC), cholesterol (CHOL) and 1,2-distearoyl-sn-glycero-3-phosphoethanolamine-N-[amino(polyethylene glycol)-2000] (mPEG2000-DSPE) in 55:40:5 molar ratio. DSF was added to the lipid mixture in 14\% ratio (mol $\mathrm{drug} / \mathrm{mol}$ lipid). The resulting lipid film was hydrated with $900 \mu \mathrm{l}$ of citric acid buffer ( $\mathrm{pH} 4.8$ ), as DSF is more stable at $\mathrm{pH}$ value of 4.5-5 [44]. The suspension was vortex mixed for 10 min and bath sonicated. The formulations were extruded (Extruder, Lipex, Vancouver, Canada) at $60{ }^{\circ} \mathrm{C}$ under nitrogen through $200 \mathrm{~nm}$ polycarbonate membrane (Costar, Corning Incorporated, NY) and then purified by gel filtration using Sepharose CL-4B columns, eluting with HEPES buffer. Liposomes were stored at $4{ }^{\circ} \mathrm{C}$.

\subsection{2. $\mathrm{Cu}(\mathrm{DDC})_{2}$ containing liposomes}

Liposomes ( $\mathrm{LipoCu}(\mathrm{DDC})_{2}-5 \% \mathrm{PEG}$ ) were prepared using a method recently described by Wehbe et al. [45] with minor modifications. The liposomes were composed of DSPC, CHOL and mPEG2000-DSPE in 55:40:5 molar ratio. Lipids were dissolved in chloroform and evaporated by rotary evaporator. The resulting lipid film was hydrated with $1 \mathrm{ml}$ of $\mathrm{CuCl}_{2}$ solution $(300 \mathrm{mM})$, vortex mixed and incubated for one hour at $60{ }^{\circ} \mathrm{C}$. Liposomes were then extruded as previously reported and purified from unencapsulated $\mathrm{CuCl}_{2}$ through chromatography on Sepharose CL-4B columns, eluting with SHE buffer [sucrose (300 mM), HEPES (20 mM) and EDTA (15 mM)] (pH 7.5). Then, a solution of DDC $\left(0.25 \mathrm{mg} / 50 \mu 1 \mathrm{MilliQ}^{\circledR}\right.$ water $)$ was added to liposomes and incubated 
for 25 minutes at room temperature. Finally, liposomal preparations were purified from unencapsulated $\mathrm{Cu}(\mathrm{DDC})_{2}$ through chromatography on Sepharose CL-4B columns, eluting with SH buffer [sucrose $(300 \mathrm{mM})$ and HEPES $(20 \mathrm{mM})$ ] $(\mathrm{pH} 7.5)$. Liposomes were stored at $4{ }^{\circ} \mathrm{C}$. To prepare HA liposomes ( $\mathrm{LipoCu}(\mathrm{DDC})_{2}-5 \% \mathrm{HA}_{4800}, \mathrm{LipoCu}(\mathrm{DDC})_{2}-5 \% \mathrm{HA}_{17000}, \mathrm{LipoCu}(\mathrm{DDC})_{2}-$ $2 \%$ PEG-3\% $\mathrm{HA}_{4800}$, and LipoCu(DDC) 2 -2\%PEG-3\%HA $\mathrm{H}_{17000}$ ), the same method was used. Lipid films were made up of DSPC/CHOL/mPEG2000-DSPE (55:40:2 molar ratio) or DSPC/CHOL (55:40 molar ratio) and then hydrated using $\mathrm{CuCl}_{2}$ solution of the different HA-DPPE conjugates (3 or 5 molar ratio).

\subsection{Liposomes characterization}

The mean particle size and polydispersity index (PDI) of the liposomes were determined at $20{ }^{\circ} \mathrm{C}$ by dynamic light scattering using a Zetasizer (Nano-ZS, Malvern instruments, UK). Size measurements were performed at a fixed angle of $173^{\circ}$ after dilution of the liposome suspensions in MilliQ $^{\circledR}$ water. Each measurement was carried out in triplicate. The surface charge of liposomes was evaluated by zeta potential measurements after dilution of the suspensions in $10 \mathrm{mM} \mathrm{KCl}$. Phospholipid phosphorous was assessed in each liposome preparation by phosphate assay after destruction with perchloric acid [46]. The amount of encapsulated DSF was determined by HPLC. Ten $\mu \mathrm{l}$ of liposomal suspension were diluted in $30 \mu \mathrm{l}$ of methanol, sonicated, vortexed and centrifuged for 5 minutes at $6000 \mathrm{x}$ g. Then, the clear supernatant was filtered with $0.45 \mu \mathrm{m}$ PTFE filters and analyzed by HPLC. The column was eluted with methanol/water (80:20 v/v) flow rate $0.8 \mathrm{ml} / \mathrm{min}$. Detection was performed by UV adsorption measurement at $275 \mathrm{~nm}$. Peak heights were recorded and processed on a CBM-10A Shimadzu interface. The drug concentration was calculated from standard curves. The assay was linear over the tested concentration range (5-50 $\mu \mathrm{g})$. Each sample was analyzed in triplicate.

The amount of $\mathrm{Cu}(\mathrm{DDC})_{2}$ incorporated into liposomes was determined by UV-VIS spectrophotometer: $20 \mu \mathrm{l}$ of liposomal suspension were diluted in $480 \mu \mathrm{l}$ of DMSO, sonicated, vortexed and centrifuged for 5 minutes at $6000 \mathrm{x} \mathrm{g}$ and the supernatant was analyzed at $435 \mathrm{~nm}$. Each sample was analyzed in triplicate. Liposomal preparations were analyzed for physical stability in the storage conditions $\left(4^{\circ} \mathrm{C}\right)$ evaluating diameter, zeta potential and drug leakage at different time intervals. Drug leakage was determined by submitting $200 \mu \mathrm{l}$ of liposomes to purification through chromatography on Sepharose CL-4B columns, eluting with HEPES buffer for DSF or SH buffer for $\mathrm{Cu}(\mathrm{DDC})_{2}$ and re-analyzing for drug and phospholipid content as described above. A change in content was interpreted as an indication of liposome instability. 


\subsubsection{Differential Scanning Calorimetry (DSC)}

DSC analysis was performed on hydrated samples. About $20 \mathrm{mg}$ of accurately weighted suspension samples were introduced into a $40 \mu \mathrm{l}$ aluminum pan and analyzed. DSC runs were conducted from $25{ }^{\circ} \mathrm{C}$ to $80{ }^{\circ} \mathrm{C}$ at a rate of $10{ }^{\circ} \mathrm{C} / \mathrm{min}$ under constant nitrogen stream $(40 \mathrm{ml} / \mathrm{min})$. The main transition temperature (Tm) was determined as the onset temperature of the highest peak. Calibration was achieved using indium $\left(\mathrm{Tm}=156.83^{\circ} \mathrm{C}\right)$ and $n$-decane $\left(\mathrm{Tm}=-29.6^{\circ} \mathrm{C}\right)$.

\subsubsection{Cryogenic Transmission Electron Microscopy (cryo-TEM)}

Empty and $\mathrm{Cu}(\mathrm{DDC})_{2}$ loaded liposomes $(30 \mathrm{mg} / \mathrm{ml})$ were diluted $5 \mathrm{X}$ in $\mathrm{SH}$ buffer and $5 \mu \mathrm{l}$ of solution were deposited onto copper grids covered with Lacey carbon film. Excess of solution was blotted off for 5 or 7 seconds using filter paper and the grids were subsequently frozen in liquid ethane using a Leica EM GP automatic system (Leica, Austria) under 90\% humidity atmosphere.

\subsection{In vitro cell studies}

\subsubsection{Cell lines}

The human Panc1 pancreatic adenocarcinoma cell line was grown in RPMI 1640 supplemented with 10\% FBS, $2 \mathrm{mM}$ glutamine, and $50 \mu \mathrm{g} / \mathrm{ml}$ gentamicin sulfate (Gibco, Thermo Fisher Scientific, Milan, Italy) at $37{ }^{\circ} \mathrm{C}$ with $5 \% \mathrm{CO}_{2}$. Panc1 CSCs were generated as previously described [8] and cultured in CSC medium, [DMEM/F-12 (US biological Life Sciences) supplemented with 1g/l glucose, B27 (Gibco, Thermo Fisher Scientific), $1 \mu \mathrm{g} / \mathrm{ml}$ fungizone (Gibco, Thermo Fisher Scientific), $1 \%$ penicillin/streptomycin (Gibco, Thermo Fisher Scientific), $5 \mu \mathrm{g} / \mathrm{ml}$ heparin (SigmaAldrich), $20 \mathrm{ng} / \mathrm{ml}$ EGF (epidermal growth factor, Peprotech, London, UK), and $20 \mathrm{ng} / \mathrm{ml}$ FGF (fibroblast growth factor, Peprotech)] at $37{ }^{\circ} \mathrm{C}$ with $5 \% \mathrm{CO}_{2}$.

\subsubsection{In vitro cytotoxicity assay}

Panc1 and Panc1 CSCs were plated in 96-well cell culture plates. Viable cells were counted by Trypan Blue dye exclusion and $7 \times 10^{3}$ cells were seeded in each well. After 24 hours both cell lines were treated with a range of concentrations from 0.05 to $100 \mu \mathrm{M}$ of DSF, $\mathrm{Zn}(\mathrm{DDC})_{2}, \mathrm{Fe}(\mathrm{DDC})_{2}$ and $\mathrm{Cu}(\mathrm{DDC})_{2}$ or liposomes (LipoDSF-5\%PEG, LipoCu(DDC) $)_{2}-5 \% \mathrm{PEG}, \mathrm{LipoCu}(\mathrm{DDC})_{2}-5 \% \mathrm{HA}_{4800}$, $\mathrm{LipoCu}(\mathrm{DDC})_{2}-5 \% \mathrm{HA}_{17000}, \quad \mathrm{LipoCu}(\mathrm{DDC})_{2}-2 \% \mathrm{PEG}-3 \% \mathrm{HA}_{4800}$, and LipoCu(DDC) 2 -2\%PEG$3 \% \mathrm{HA}_{17000}$ ). Cell viability was evaluated using resazurin Cell Viability Assay Kit (Immunological Science, Rome, Italy), which is an indicator of cell viability by converting resazurin, a non- 
fluorescent dye, to resorufin, a highly red fluorescent dye, in response to chemical reduction of growth medium due to cell growth. Sixty $\mu$ l of resazurin solution $(10 \mu 1$ of resazurin and $50 \mu 1$ of fresh medium) were added in each well. After 1 hour, the fluorescent signal was monitored using $535 \mathrm{~nm}$ excitation wavelength and $590 \mathrm{~nm}$ emission wavelength. The fluorescent signal generated from the assay is proportional to the number of living cells in the well. Three independent experiments were performed for each condition and cell viability was reported as the percentage relative to control.

\subsubsection{ROS analyses}

The non-fluorescent diacetylated 2,7-dichlorofluorescein (DCF-DA) probe (Sigma-Aldrich), which becomes highly fluorescent upon oxidation, was used to evaluate intracellular ROS production. Briefly, cells were plated in 96-well plates $\left(1 \times 10^{4}\right.$ cells/well) and, the day after, were treated with the various compounds at the indicated concentrations for 24 hours. At the end of the various treatments, the cells were incubated in culture medium with $10 \mu \mathrm{M} \mathrm{DCF}-\mathrm{DA}$ for $15 \mathrm{~min}$ at $37^{\circ} \mathrm{C}$. The cells were washed with PBS and the DCF fluorescence was measured by using a multimode plate reader (Ex485 nm and Em535 nm) (GENios Pro, Tecan). The values were normalized on cell number by using trypan blue solution.

\subsubsection{Glutathione analyses}

Metabolites were extracted as previously reported [47]. Analyses were performed with an Ultimate 3000 Rapid Resolution HPLC system (LC Packings, DIONEX, Sunnyvale, CA) and an electrospray hybrid quadrupole time-of-flight instrument MicroTOF-Q (Bruker-Daltonik, Bremen, Germany) equipped with an ESI-ion source. The procedures and technical settings used were consistent with our previous investigation [47]. Because calibration of the mass analyzer is essential in order to maintain a high level of mass accuracy, instrument calibration was performed externally every day with a sodium formate solution consisting of $10 \mathrm{mM}$ sodium hydroxide in 50\% isopropanol: water, $0.1 \%$ formic acid. Automated internal mass scale calibration was performed through direct automated injection of the calibration solution at the beginning and at the end of each run by a 6port divert-valve. Metabolite data elaboration was performed through MAVEN.52; mass spectrometry chromatograms were elaborated for peak alignment, matching and comparison of parent and fragment ions, and tentative metabolite identification (within a 10 ppm mass-deviation range between observed and expected results against the imported KEGG database).

\subsubsection{Primary human pancreatic cancer cells}


Human PDAC tissues were obtained with written informed consent from all patients. Primary cultures of freshly retrieved cancer cells were obtained from patients with advanced pancreatic cancer (C75, C76, C102) or from in vivo patient-derived xenografts (PDX) (A6L, 12556). Tumors were minced, enzymatically digested with collagenase (STEMCELL Technologies, Vancouver, Canada) and, after centrifugation, cell pellets were resuspended and cultured in RPMI1640 supplemented with $10 \%$ FBS and $50 \mathrm{U} / \mathrm{ml}$ penicillin-streptomycin. PDX-derived tumor cells were cultured until passage 10 [48].

A6L, 12556, C75, C76 and C102 cells were plated in 96-well cell culture plates. Viable cells were counted by Trypan Blue dye exclusion and $3 \times 10^{3}$ cells were seeded in each well and cultured as spheres with DMEM:F12 supplemented with B27 and bFGF in anchorage independent suspension conditions for 3 days (first generation spheres). First generation tumor spheres were harvested using a $40 \mu \mathrm{m}$ cell strainer, dissociated into single cells by trypsinization, and then re-cultured for additional 7 days (second generation spheres). After 3 days, spheres were treated with $0.1 \mu \mathrm{M}$ of DSF, $\mathrm{Cu}(\mathrm{DDC})_{2}, \mathrm{LipoCu}(\mathrm{DDC})_{2}-5 \%$ PEG or LipoCu(DDC) $)_{2}-2 \%$ PEG-3\%HA 17000 for 24 hours. Cell viability was evaluated using resazurin Cell Viability Assay Kit as described in section 2.6.2. Three independent experiments were performed for each condition and cell viability was reported as the percentage relative to control.

\subsubsection{Sphere formation assay}

Pancreatic cancer spheres of first and second generation were obtained by culturing primary pancreatic cancer cells as described in section 2.6.5. Ten thousands cells were seeded in each well in 24-well cell culture plate and incubated for 3 days. Then, first and second generation spheres were treated with $0.1 \mu \mathrm{M}$ of DSF, $\mathrm{Cu}(\mathrm{DDC})_{2}$, LipoCu(DDC $)_{2}-5 \%$ PEG or LipoCu(DDC $)_{2}-2 \%$ PEG3\% $\mathrm{HA}_{17000}$ for 4 days. After treatment, a CASY Cell Counter (Roche Applied Sciences, Mannheim, Germany) was used to quantify spheres with a diameter $>40 \mu \mathrm{m}$. Each condition was performed in triplicate.

\subsubsection{Statistical analysis}

ANOVA (post hoc Bonferroni) analysis was performed by GraphPad Prism 5 (GraphPad Software) and used for multiple-group comparison. Student's t-test was used for individual group comparison. $\mathrm{P}$-values $<0.05,0.01,0.001$ were indicated as $*, * *, * * *$, respectively.

\section{Results and discussion}




\subsection{Synthesis and cytotoxic activity of DDC-metal complexes}

As widely reported in the literature, DSF and dithiocarbamates are able to form stable complexes with metals such as copper, zinc, gold, and iron [49]. The resulting complexes show the ability to inhibit proteasome, metalloproteinases and to induce ROS production [24, 27, 50].

In this work, complexes between DSF active metabolite DDC and zinc, iron and copper were prepared by mixing aqueous solution of the corresponding salts with DDC. The complexation was instantaneous and visible because of the formation of a considerable amount of precipitate. MS analysis confirmed the formation of the complexes revealing that two molecules of DDC were complexed with one atom of metal and indicating that the resulting structure was the same that could be obtained in the reaction between DSF and metals. We decided to use DDC instead of DSF for two reasons. First, because the purification process of the complexes was easier due to the water solubility of both reagents, DDC and metal salts, which were easily separated from the product by water washing. Second, because the method used to prepare liposomes containing $\mathrm{Cu}(\mathrm{DDC})_{2}$ involved the use of DDC to obtain the formation of the complex inside the liposomes (see below). The antitumor activity of DDC/metal complexes was evaluated, at doses ranging from 0 to $100 \mu \mathrm{M}$, on Panc1 parental cell line or the derived Panc1 CSCs. $\mathrm{Cu}(\mathrm{DDC})_{2}$ was significantly more efficacious than $\mathrm{DSF}, \mathrm{Zn}(\mathrm{DDC})_{2}$ and $\mathrm{Fe}(\mathrm{DDC})_{2}$, inducing a concentration-dependent reduction of growth on both cell lines (Fig. 1, Table 1). Treatments of 72 hours with $\mathrm{Cu}(\mathrm{DDC})_{2}$ showed a greater inhibition of cell growth resulting in a total mortality even at low doses both in Panc1 cells and Panc1 CSCs (Fig. $1 \mathrm{~B}$ and D), with $\mathrm{IC}_{50}$ values of $0.68 \pm 0.16$ and $0.35 \pm 0.03$, respectively (Table 1). These results demonstrate that $\mathrm{Cu}(\mathrm{DDC})_{2}$ possesses the strongest antitumor activity in our cell models. For this reason and for its well documented anticancer activity $[15,19], \mathrm{Cu}(\mathrm{DDC})_{2}$ was chosen for the following experiments.

\subsection{Preparation and characterization of liposomes}

\subsubsection{DSF containing liposomes}

This preparation was especially elaborated to find the suitable phospholipidic mixture able to prevent drug leakage. In particular, formulations containing L- $\alpha$-phosphatidylcholine or 1,2dipalmitoyl-sn-glycero-3-phosphocholine with different amounts of CHOL (from 10\% to 40\%) were not stable and after 24 hours at $4{ }^{\circ} \mathrm{C}$ the total amount of encapsulated DSF was released from liposomes. For this reason, a "rigid" formulation composed of a phospholipid with a high transition temperature (DSPC) and $40 \%$ of CHOL was prepared in order to prevent rapid drug leakage. These 
liposomes displayed a mean size of about $165 \mathrm{~nm}$, low polydispersity index (PDI<0.1) and negative zeta potential value. Despite favorable characteristics of DSF, i.e. low molecular weight and lipophilic structure, its entrapment efficiency (EE) was around 65\% (Table 2) corresponding to a final drug loading of $0.8 \%$ (mg of drug per mg of phospholipids). However, it is important to note that to obtain a stable liposome formulation, the amount of CHOL was increased to $40 \%$ and this probably hampered the complete encapsulation of DSF into the phospholipid bilayer.

Liposome stability was evaluated in HEPES buffer at $4{ }^{\circ} \mathrm{C}$ by measuring, at various times, mean diameter, zeta potential value, drug leakage and phospholipid content. Liposomes were stable for 35 days maintaining $80 \%$ of their initial drug content. Over this period, no appreciable size change $(<10 \%)$ and liposome precipitation were observed as well as no change in zeta potential.

\subsection{2. $\mathrm{Cu}(\mathrm{DDC})_{2}$ containing liposomes}

$\mathrm{Cu}(\mathrm{DDC})_{2}$ containing liposomes were prepared by using the method described by Wehbe et al. [45, 51], which provides the formation of the active $\mathrm{Cu}(\mathrm{DDC})_{2}$ complex inside the preformed liposomes and its consequent precipitation within the aqueous core in a single step. The method is based on the different membrane permeability of DDC compared to the complex. Indeed, DDC is water soluble and membrane permeable while the copper complex is water insoluble and membrane impermeable. The lipid film composed of DSPC, CHOL and mPEG-DSPE in 55:40:5 molar ratio was hydrated with a solution of $\mathrm{CuCl}_{2}$ and incubated at $60{ }^{\circ} \mathrm{C}$, then the $\mathrm{CuCl}_{2}$ was eliminated by gel filtration and liposomes containing $\mathrm{CuCl}_{2}$ in the aqueous core were obtained. Then, DDC was added to the liposomes and incubated at room temperature and a drastic color change from light blue to brown was observed indicating the occurred complex formation. Finally, non encapsulated $\mathrm{Cu}(\mathrm{DDC})_{2}$ was removed by gel filtration.

In order to prepare hyaluronic acid decorated liposomes, the conjugates $\mathrm{HA}_{4800}-\mathrm{DPPE}$ or $\mathrm{HA}_{17000^{-}}$ DPPE, in molar ratio of 3 or $5 \%$, were added during the hydration phase of lipid film. In this way, the phospholipidic chain was incorporated into the liposome membrane, while the HA was exposed toward the aqueous phase. Liposomes displayed a dimensional range from about $165 \mathrm{~nm}$ to $225 \mathrm{~nm}$ and the particle size of the HA-liposomes tended to increase with the increase of polymer MW. The PDI was low for all the formulations $(<0.2)$ and the zeta potential value was negative and lower for HA-liposomes compared to the plain ones, due to the carboxylic negative residues of HA. In particular, the negative charge increased with the increase of HA MW (Table 2). These data confirmed the presence of HA on the surface of the liposomes.

The formulations showed a good EE (Table 2), which was similar for plain liposomes and for liposomes decorated with $\mathrm{HA}_{4800}$-DPPE or $\mathrm{HA}_{17000}$-DPPE, indicating that the method of 
encapsulation ensured high drug loading and that the introduction of the HA-DPPE conjugates did not affect the $\mathrm{Cu}(\mathrm{DDC})_{2}$ encapsulation. The final drug loading was about $4 \%$ for all the liposomal formulations. All formulations were stable at $4{ }^{\circ} \mathrm{C}$ for at least 35 days, as shown by the unchanged values of drug leakage, size and zeta potential over this period.

\subsubsection{Differential Scanning Calorimetry (DSC)}

In order to evaluate the interactions between DSF and the liposome membrane, a DSC analysis was performed (Fig. 2). The thermogram of pure DSPC presented the main transition, related to the passage from the ripple gel phase $\left(\mathrm{P}_{\beta}\right)$ to the lamellar liquid-crystalline phase $\left(\mathrm{L}_{\alpha}\right)$, at $\mathrm{T}_{\text {onset }} 54.3$ ${ }^{\circ} \mathrm{C}$. In the presence of mPEG-DSPE, no significant changes in the transition temperature were observed $\left(\mathrm{T}_{\text {onset }} 54.0^{\circ} \mathrm{C}\right)$, but a slight enlargement of the peak appeared. When DSF was added, the main transition was shifted to lower temperatures, $\mathrm{T}_{\text {onset }} 52.8{ }^{\circ} \mathrm{C}$, and a substantial broadening of melting temperature peaks was observed, indicating that DSF interacts with the liposome bilayer through hydrophobic interactions by perturbing the phase transition behavior.

\subsubsection{Cryogenic Transmission Electron Microscopy (cryo-TEM)}

The morphology of $\mathrm{Cu}(\mathrm{DDC})_{2}$ liposomes was evaluated by cryo-TEM analysis. In Fig. 3, the images relative to the empty (A) or loaded non-decorated formulations (Fig. 3B-F) are shown. It is possible to note the presence of unilamellar and multilamellar liposomes, probably due to the limited number of extrusion cycles performed. Liposomes showed the typical spherical shape or, in few cases, elongated shape due to the pressure exerted by ice layer, and presented slightly different sizes. The most interesting observation was the presence of needle-shaped structures (Fig. 3 C-F) representing stacked $\mathrm{Cu}(\mathrm{DDC})_{2}$ complexes precipitated inside the aqueous core of liposomes in the form of crystals.

\subsection{Studies on cells}

3.3.1 $\mathrm{Cu}(\mathrm{DDC})_{2}$ containing liposomes possess a strong anti-proliferative activity on Pancl cells and Pancl CSCS

The liposomal formulation containing DSF (LipoDSF-5\%PEG) was significantly more active than free DSF, only after 72 hours of treatment, in both cell lines, as shown by the $\mathrm{IC}_{50}$ values in Table 1 and by the cell growth curve in Supplementary material Fig. S1. Moreover, Panc1 CSCs were more sensitive than Panc1 to LipoDSF-5\%PEG treatment at both incubation times (Table 1). Loading of 
$\mathrm{Cu}(\mathrm{DDC})_{2}$ into the liposomes strongly increased the anti-proliferative effect of $\mathrm{Cu}(\mathrm{DDC})_{2}$. As reported in Fig. 4, LipoCu(DDC $)_{2}-5 \%$ PEG showed a higher anti-proliferative activity than $\mathrm{Cu}(\mathrm{DDC})_{2}$ in Panc1 and Panc1 CSCs, resulting in a concentration dose-dependent reduction of cell growth and lower $\mathrm{IC}_{50}$ values (Table 1). To investigate the targeting ability of HA towards CD44expressing tumor cells, the anti-proliferative effect of $\mathrm{Cu}(\mathrm{DDC})_{2}$ loaded in liposomes coated with HA with two different MW and/or with different percentage of PEG was evaluated. Liposomal formulations containing either PEG or HA determined a similar inhibition of cell proliferation, whereas the presence of both PEG and $\mathrm{HA}_{17000}$ further increased the anti-proliferative activity of $\mathrm{Cu}(\mathrm{DDC})_{2}$ at 24 hours (Fig. 4 and Table 1), in both cell lines. Furthermore, after 72 hours of treatment, Panc1 CSCs were more sensitive to liposome formulations with $\mathrm{HA}_{17000}$ and/or PEG compared to Panc1 cells (Table 1). Interestingly, when the anti-proliferative effect was examined at a concentration of the $\mathrm{Cu}(\mathrm{DDC})_{2}$ as low as $0.1 \mu \mathrm{M}$, Panc1 CSCs were highly sensitive to liposomal formulations, with HA coated liposomes being more active than the plain ones, while Panc1 cells were completely resistant (Fig. 5). Altogether, these results demonstrate that liposomes coated with $2 \% \mathrm{PEG}$ and $3 \% \mathrm{HA}_{17000}$ are the most effective tested formulation on both cell lines, with a higher efficacy on CSCs markedly at low $\mathrm{Cu}(\mathrm{DDC})_{2}$ concentration, suggesting that it could be used in PDAC therapy.

3.3.2. Reactive oxygen species (ROS) are responsible for the higher anti-proliferative activity of LipoCu(DDC $)_{2}-2 \%$ PEG-3\%HA 17000 on Pancl CSCs compared to parental cells

$\mathrm{Cu}(\mathrm{DDC})_{2}$ has been described as an ionophore complex able to induce a copper-mediated ROS increase that can promote a mitochondrial-mediated cell death program [21]. To verify whether ROS were responsible for the higher anti-proliferative activity of LipoCu(DDC $)_{2}-2 \%$ PEG$3 \% \mathrm{HA}_{17000}$ on Panc1 CSCs compared to parental cells, we measured ROS production on Panc1 cells and Panc1 CSCs at the constitutive level and after treatment with LipoCu(DDC) 2 - $2 \%$ PEG$3 \% \mathrm{HA}_{17000}$ containing $0.1 \mu \mathrm{M}$ of $\mathrm{Cu}(\mathrm{DDC})_{2}$. In parallel, we determined the effect of ROS neutralization on cell growth. Figure 6 shows that constitutive ROS levels were significantly higher in CSCs compared to parental cells (Fig. 6 A) and they increased after treatment only in CSCs (Fig. 6 B). Neutralization of ROS with N-acetyl-L-cysteine (NAC) almost completely recovered cell viability (Fig. $6 \mathrm{C}$ ), indicating that ROS play a major role in CSC growth inhibition by LipoCu(DDC) $)_{2}-2 \%$ PEG-3\% $\mathrm{HA}_{17000}$.

The observation that constitutive ROS levels were higher in Panc1 CSCs compared to parental cells prompted us to investigate the cellular status of GSH/glutathione disulphide, the major redox couple in animal cells. Figure 6 D indicates that the ratio GSH/GSSG is lower in Panc1 CSCs, consistently 
with the higher amount of ROS compared to parental cells. This result strongly suggests that Panc1 CSCs are more susceptible to the oxidative stress induced by $\mathrm{Cu}(\mathrm{DDC})_{2}$ probably because of an alteration of their metabolism leading to increased ROS and the consequential increased consumption of GSH. Indeed, we have recently published that Panc1 CSCs display, compared to Panc1 parental cells, a more glycolytic phenotype [47], which is known to maintain a high nontoxic oxidative stress in cancer cells [52].

3.3.3. $\mathrm{Cu}(\mathrm{DDC})_{2}$ containing liposomes possess a strong anti-proliferative activity on cells derived from PDAC patients

To evaluate whether the liposome formulations were active also on a cellular context clinically relevant, we tested their anti-proliferative activity in comparison to $\mathrm{DSF}$ and $\mathrm{Cu}(\mathrm{DDC})_{2}$ on pancreatic cancer cells directly obtained from patients affected by PDAC. The primary cells 12556, A6L, C75, C76, and C102 were cultured as spheres, as described in Materials and Methods, and treated with $0.1 \mu \mathrm{M}$ of the formulations mentioned above. Cell viability was evaluated after 24 hours of treatment. As shown in Fig. 7, the liposome formulations containing $\mathrm{Cu}(\mathrm{DDC})_{2}$ were more effective than free compounds on first generation spheres and even more on second generation spheres. These data are particularly interesting since they show a strong anti-proliferative effect of $\mathrm{Cu}(\mathrm{DDC})_{2}$ containing liposomes on cells derived from PDAC patients having stem like features. Furthermore, they open the way to the clinical use of $\mathrm{Cu}(\mathrm{DDC})_{2}$ liposomal formulations due to their suitability for intravenous administration.

\subsection{Effect of DSF and DSF containing liposomes on sphere formation capability}

In the context of CSC features, the sphere formation capability is generally studied in vitro and used to identify new ways for targeting CSCs [48]. A specific method for culturing primary human pancreatic cancer cells from tissues resected during surgery was used in order to obtain tumor spheres of first or second generation. In Fig. 8, the effect of DSF, $\mathrm{Cu}(\mathrm{DDC})_{2}, \mathrm{LipoCu}(\mathrm{DDC})_{2^{-}}$ $5 \% \mathrm{PEG}$ and $\mathrm{LipoCu}(\mathrm{DDC})_{2}-2 \% \mathrm{PEG}-3 \% \mathrm{HA}_{17000}$ on the in vitro sphere formation capability is shown. Liposome formulations at $0.1 \mu \mathrm{M}$ of $\mathrm{Cu}(\mathrm{DDC})_{2}$ decreased the number of first generation spheres, while DSF and $\mathrm{Cu}(\mathrm{DDC})_{2}$ treatment slightly affected or did not affect sphere number. Also the cellular morphology was affected by liposome formulation treatment (Supplementary material Fig. S2), as shown by the loss of the typical shape of the spheres, which appeared similar to small cell aggregates. The first generation spheres were subsequently passaged into second generation spheres and also the formation of these spheres was drastically reduced (Fig. 8). Thus, our data 
demonstrate a significant inhibitory effect of liposome formulations on the capacity of primary pancreatic cancer stem like cells to form spheres, which is a typical feature of these cells.

\section{Conclusions}

The results described in this paper are of great relevance from clinical point of view since, for the first time to our knowledge, they open the way to consider liposomes decorated with HA and encapsulating the potent anti-proliferative $\mathrm{Cu}(\mathrm{DDC})_{2}$ complex as a potent therapeutic tool against PDAC. Indeed, it has been widely reported that PDAC initiation, growth, metastasis and resistance to therapy are driven by CSCs and our impressive data on primary cells with a stem like phenotype directly derived from PDAC patients show the high capacity of $\mathrm{Cu}(\mathrm{DDC})_{2}$ liposomal formulations to inhibit the proliferation and the sphere forming capability of these cells.

\section{Acknowledgements}

Funding from Italian Ministry for University and Research (MIUR) - University of Torino, "Fondi Ricerca Locale (ex-60\%)" are kindly acknowledged. This work was supported by Joint Projects program 2017 from University of Verona to M. Palmieri. Ilaria Dando is a fellow of Fondazione Umberto Veronesi. Authors would like to thank Mehrez Sghaier for help with DSC experiments. The present work has benefited also from the core facilities of Imagerie-Gif, (http://www.i2bc.paris-saclay.fr), member of IBiSA (http://www.ibisa.net), supported by "France-BioImaging" (ANR-10-INBS-04-01), and the Labex "Saclay Plant Science" (ANR-11-IDEX-0003-02). Institut Galien Paris-Sud is a member of the Laboratory of Excellence LERMIT supported by a grant from ANR (ANR-10-LABX-33). 


\section{References}

[1] R.L. Siegel, K.D. Miller, A. Jemal, Cancer statistics, 2016, CA: a cancer journal for clinicians, 66 (2016) 7-30.

[2] M.F. Eskander, L.A. Bliss, J.F. Tseng, Pancreatic adenocarcinoma, Current problems in surgery, 53 (2016) 107-154.

[3] C. Li, D.G. Heidt, P. Dalerba, C.F. Burant, L. Zhang, V. Adsay, M. Wicha, M.F. Clarke, D.M. Simeone, Identification of pancreatic cancer stem cells, Cancer research, 67 (2007) 1030-1037.

[4] P.C. Hermann, S.L. Huber, T. Herrler, A. Aicher, J.W. Ellwart, M. Guba, C.J. Bruns, C. Heeschen, Distinct populations of cancer stem cells determine tumor growth and metastatic activity in human pancreatic cancer, Cell stem cell, 1 (2007) 313-323.

[5] Z.A. Rasheed, J. Yang, Q. Wang, J. Kowalski, I. Freed, C. Murter, S.M. Hong, J.B. Koorstra, N.V. Rajeshkumar, X. He, M. Goggins, C. Iacobuzio-Donahue, D.M. Berman, D. Laheru, A. Jimeno, M. Hidalgo, A. Maitra, W. Matsui, Prognostic significance of tumorigenic cells with mesenchymal features in pancreatic adenocarcinoma, Journal of the National Cancer Institute, 102 (2010) 340-351.

[6] J.E. Visvader, G.J. Lindeman, Cancer stem cells: current status and evolving complexities, Cell stem cell, 10 (2012) 717-728.

[7] E. Lonardo, P.C. Hermann, M.T. Mueller, S. Huber, A. Balic, I. Miranda-Lorenzo, S. Zagorac, S. Alcala, I. Rodriguez-Arabaolaza, J.C. Ramirez, R. Torres-Ruiz, E. Garcia, M. Hidalgo, D.A. Cebrian, R. Heuchel, M. Lohr, F. Berger, P. Bartenstein, A. Aicher, C. Heeschen, Nodal/Activin signaling drives self-renewal and tumorigenicity of pancreatic cancer stem cells and provides a target for combined drug therapy, Cell stem cell, 9 (2011) 433-446.

[8] E. Dalla Pozza, I. Dando, G. Biondani, J. Brandi, C. Costanzo, E. Zoratti, M. Fassan, F. Boschi, D. Melisi, D. Cecconi, M.T. Scupoli, A. Scarpa, M. Palmieri, Pancreatic ductal adenocarcinoma cell lines display a plastic ability to bidirectionally convert into cancer stem cells, International journal of oncology, 46 (2015) 1099-1108.

[9] A. Jimeno, G. Feldmann, A. Suarez-Gauthier, Z. Rasheed, A. Solomon, G.M. Zou, B. RubioViqueira, E. Garcia-Garcia, F. Lopez-Rios, W. Matsui, A. Maitra, M. Hidalgo, A direct pancreatic cancer xenograft model as a platform for cancer stem cell therapeutic development, Molecular cancer therapeutics, 8 (2009) 310-314.

[10] H. Wang, P. Agarwal, S. Zhao, R.X. Xu, J. Yu, X. Lu, X. He, Hyaluronic acid-decorated dual responsive nanoparticles of Pluronic F127, PLGA, and chitosan for targeted co-delivery of doxorubicin and irinotecan to eliminate cancer stem-like cells, Biomaterials, 72 (2015) 74-89.

[11] E. Muntimadugu, R. Kumar, S. Saladi, T.A. Rafeeqi, W. Khan, CD44 targeted chemotherapy for co-eradication of breast cancer stem cells and cancer cells using polymeric nanoparticles of salinomycin and paclitaxel, Colloids Surf B Biointerfaces, 143 (2016) 532-546.

[12] D. Cen, R.I. Gonzalez, J.A. Buckmeier, R.S. Kahlon, N.B. Tohidian, F.L. Meyskens, Jr., Disulfiram induces apoptosis in human melanoma cells: a redox-related process, Molecular cancer therapeutics, 1 (2002) 197-204.

[13] H. Lovborg, F. Oberg, L. Rickardson, J. Gullbo, P. Nygren, R. Larsson, Inhibition of proteasome activity, nuclear factor-KappaB translocation and cell survival by the antialcoholism drug disulfiram, International journal of cancer, 118 (2006) 1577-1580.

[14] H.J. Cho, T.S. Lee, J.B. Park, K.K. Park, J.Y. Choe, D.I. Sin, Y.Y. Park, Y.S. Moon, K.G. Lee, J.H. Yeo, S.M. Han, Y.S. Cho, M.R. Choi, N.G. Park, Y.S. Lee, Y.C. Chang, Disulfiram suppresses invasive ability of osteosarcoma cells via the inhibition of MMP-2 and MMP-9 expression, Journal of biochemistry and molecular biology, 40 (2007) 1069-1076.

[15] D. Chen, Q.C. Cui, H. Yang, Q.P. Dou, Disulfiram, a clinically used anti-alcoholism drug and copper-binding agent, induces apoptotic cell death in breast cancer cultures and xenografts via inhibition of the proteasome activity, Cancer research, 66 (2006) 10425-10433. 
[16] V.T. Cheriyan, Y. Wang, M. Muthu, S. Jamal, D. Chen, H. Yang, L.A. Polin, A.L. Tarca, H.I. Pass, Q.P. Dou, S. Sharma, A. Wali, A.K. Rishi, Disulfiram suppresses growth of the malignant pleural mesothelioma cells in part by inducing apoptosis, PloS one, 9 (2014) e93711.

[17] K. Iljin, K. Ketola, P. Vainio, P. Halonen, P. Kohonen, V. Fey, R.C. Grafstrom, M. Perala, O. Kallioniemi, High-throughput cell-based screening of 4910 known drugs and drug-like small molecules identifies disulfiram as an inhibitor of prostate cancer cell growth, Clinical cancer research : an official journal of the American Association for Cancer Research, 15 (2009) 60706078.

[18] X. Lun, J.C. Wells, N. Grinshtein, J.C. King, X. Hao, N.H. Dang, X. Wang, A. Aman, D. Uehling, A. Datti, J.L. Wrana, J.C. Easaw, A. Luchman, S. Weiss, J.G. Cairncross, D.R. Kaplan, S.M. Robbins, D.L. Senger, Disulfiram when Combined with Copper Enhances the Therapeutic Effects of Temozolomide for the Treatment of Glioblastoma, Clinical cancer research : an official journal of the American Association for Cancer Research, 22 (2016) 3860-3875.

[19] X. Guo, B. Xu, S. Pandey, E. Goessl, J. Brown, A.L. Armesilla, J.L. Darling, W. Wang, Disulfiram/copper complex inhibiting NFkappaB activity and potentiating cytotoxic effect of gemcitabine on colon and breast cancer cell lines, Cancer letters, 290 (2010) 104-113.

[20] S.S. Brar, C. Grigg, K.S. Wilson, W.D. Holder, Jr., D. Dreau, C. Austin, M. Foster, A.J. Ghio, A.R. Whorton, G.W. Stowell, L.B. Whittall, R.R. Whittle, D.P. White, T.P. Kennedy, Disulfiram inhibits activating transcription factor/cyclic AMP-responsive element binding protein and human melanoma growth in a metal-dependent manner in vitro, in mice and in a patient with metastatic disease, Molecular cancer therapeutics, 3 (2004) 1049-1060.

[21] E. Dalla Pozza, M. Donadelli, C. Costanzo, T. Zaniboni, I. Dando, M. Franchini, S. Arpicco, A. Scarpa, M. Palmieri, Gemcitabine response in pancreatic adenocarcinoma cells is synergistically enhanced by dithiocarbamate derivatives, Free Radic Biol Med, 50 (2011) 926-933.

[22] J.Y. Kim, Y. Cho, E. Oh, N. Lee, H. An, D. Sung, T.-M. Cho, J.H. Seo, Disulfiram targets cancer stem-like properties and the HER2/Akt signaling pathway in HER2-positive breast cancer, Cancer letters, 379 (2016) 39-48.

[23] P. Liu, S. Brown, T. Goktug, P. Channathodiyil, V. Kannappan, J.P. Hugnot, P.O. Guichet, X. Bian, A.L. Armesilla, J.L. Darling, W. Wang, Cytotoxic effect of disulfiram/copper on human glioblastoma cell lines and ALDH-positive cancer-stem-like cells, British journal of cancer, 107 (2012) 1488-1497.

[24] J. Han, L. Liu, X. Yue, J. Chang, W. Shi, Y. Hua, A binuclear complex constituted by diethyldithiocarbamate and copper(I) functions as a proteasome activity inhibitor in pancreatic cancer cultures and xenografts, Toxicology and applied pharmacology, 273 (2013) 477-483.

[25] A. Paranjpe, R. Zhang, F. Ali-Osman, G.C. Bobustuc, K.S. Srivenugopal, Disulfiram is a direct and potent inhibitor of human O6-methylguanine-DNA methyltransferase (MGMT) in brain tumor cells and mouse brain and markedly increases the alkylating DNA damage, Carcinogenesis, 35 (2014) 692-702.

[26] T.W. Loo, M.C. Bartlett, D.M. Clarke, Disulfiram metabolites permanently inactivate the human multidrug resistance P-glycoprotein, Molecular pharmaceutics, 1 (2004) 426-433.

[27] J.L. Allensworth, M.K. Evans, F. Bertucci, A.J. Aldrich, R.A. Festa, P. Finetti, N.T. Ueno, R. Safi, D.P. McDonnell, D.J. Thiele, S. Van Laere, G.R. Devi, Disulfiram (DSF) acts as a copper ionophore to induce copper-dependent oxidative stress and mediate anti-tumor efficacy in inflammatory breast cancer, Molecular oncology, 9 (2015) 1155-1168.

[28] R.K. Kankala, C.-G. Liu, A.-Z. Chen, S.-B. Wang, P.-Y. Xu, L.K. Mende, C.-L. Liu, C.-H. Lee, Y.-F. Hu, Overcoming Multidrug Resistance through the Synergistic Effects of Hierarchical pH-Sensitive, ROS-Generating Nanoreactors, ACS Biomaterials Science \& Engineering, 3 (2017) 2431-2442.

[29] R.K. Kankala, Y. Kuthati, C.-L. Liu, C.-Y. Mou, C.-H. Lee, Killing cancer cells by delivering a nanoreactor for inhibition of catalase and catalytically enhancing intracellular levels of ROS, RSC Advances, 5 (2015) 86072-86081. 
[30] R.K. Kankala, P.-Y. Tsai, Y. Kuthati, P.-R. Wei, C.-L. Liu, C.-H. Lee, Overcoming multidrug resistance through co-delivery of ROS-generating nano-machinery in cancer therapeutics, Journal of Materials Chemistry B, 5 (2017) 1507-1517.

[31] B. Johansson, A review of the pharmacokinetics and pharmacodynamics of disulfiram and its metabolites, Acta psychiatrica Scandinavica. Supplementum, 369 (1992) 15-26.

[32] D. Peer, J.M. Karp, S. Hong, O.C. Farokhzad, R. Margalit, R. Langer, Nanocarriers as an emerging platform for cancer therapy, Nature nanotechnology, 2 (2007) 751-760.

[33] A. Akbarzadeh, R. Rezaei-Sadabady, S. Davaran, S.W. Joo, N. Zarghami, Y. Hanifehpour, M. Samiei, M. Kouhi, K. Nejati-Koshki, Liposome: classification, preparation, and applications, Nanoscale research letters, 8 (2013) 102.

[34] P.P. Deshpande, S. Biswas, V.P. Torchilin, Current trends in the use of liposomes for tumor targeting, Nanomedicine (London, England), 8 (2013) 1509-1528.

[35] V. Torchilin, Antibody-modified liposomes for cancer chemotherapy, Expert opinion on drug delivery, 5 (2008) 1003-1025.

[36] A. Accardo, G. Morelli, Review peptide-targeted liposomes for selective drug delivery: Advantages and problematic issues, Biopolymers, 104 (2015) 462-479.

[37] A. Gabizon, D. Tzemach, J. Gorin, L. Mak, Y. Amitay, H. Shmeeda, S. Zalipsky, Improved therapeutic activity of folate-targeted liposomal doxorubicin in folate receptor-expressing tumor models, Cancer chemotherapy and pharmacology, 66 (2010) 43-52.

[38] W. Alshaer, H. Hillaireau, J. Vergnaud, S. Ismail, E. Fattal, Functionalizing Liposomes with anti-CD44 Aptamer for Selective Targeting of Cancer Cells, Bioconjugate chemistry, 26 (2015) 1307-1313.

[39] X.P. Li, X.W. Zhang, L.Z. Zheng, W.J. Guo, Expression of CD44 in pancreatic cancer and its significance, International journal of clinical and experimental pathology, 8 (2015) 6724-6731.

[40] G. Mattheolabakis, L. Milane, A. Singh, M.M. Amiji, Hyaluronic acid targeting of CD44 for cancer therapy: from receptor biology to nanomedicine, Journal of drug targeting, 23 (2015) 605618.

[41] S. Misra, P. Heldin, V.C. Hascall, N.K. Karamanos, S.S. Skandalis, R.R. Markwald, S. Ghatak, Hyaluronan-CD44 interactions as potential targets for cancer therapy, The FEBS journal, 278 (2011) 1429-1443.

[42] S. Arpicco, C. Lerda, E. Dalla Pozza, C. Costanzo, N. Tsapis, B. Stella, M. Donadelli, I. Dando, E. Fattal, L. Cattel, M. Palmieri, Hyaluronic acid-coated liposomes for active targeting of gemcitabine, European journal of pharmaceutics and biopharmaceutics : official journal of Arbeitsgemeinschaft fur Pharmazeutische Verfahrenstechnik e.V, 85 (2013) 373-380.

[43] E. Dalla Pozza, C. Lerda, C. Costanzo, M. Donadelli, I. Dando, E. Zoratti, M.T. Scupoli, S. Beghelli, A. Scarpa, E. Fattal, S. Arpicco, M. Palmieri, Targeting gemcitabine containing liposomes to CD44 expressing pancreatic adenocarcinoma cells causes an increase in the antitumoral activity, Biochimica et biophysica acta, 1828 (2013) 1396-1404.

[44] X. Chen, L. Zhang, X. Hu, X. Lin, Y. Zhang, X. Tang, Formulation and preparation of a stable intravenous disulfiram-loaded lipid emulsion, European Journal of Lipid Science and Technology, 117 (2015) 869-878.

[45] M. Wehbe, M. Anantha, I. Backstrom, A. Leung, K. Chen, A. Malhotra, K. Edwards, M.B. Bally, Nanoscale Reaction Vessels Designed for Synthesis of Copper-Drug Complexes Suitable for Preclinical Development, PloS one, 11 (2016) e0153416.

[46] G.R. Bartlett, Phosphorus assay in column chromatography, The Journal of biological chemistry, 234 (1959) 466-468.

[47] J. Brandi, I. Dando, E.D. Pozza, G. Biondani, R. Jenkins, V. Elliott, K. Park, G. Fanelli, L. Zolla, E. Costello, A. Scarpa, D. Cecconi, M. Palmieri, Proteomic analysis of pancreatic cancer stem cells: Functional role of fatty acid synthesis and mevalonate pathways, J Proteomics, 150 (2017) 310-322. 
[48] E. Lonardo, M. Cioffi, P. Sancho, S. Crusz, C. Heeschen, Studying Pancreatic Cancer Stem Cell Characteristics for Developing New Treatment Strategies, Journal of visualized experiments : JoVE, (2015) e52801.

[49] D. Buac, S. Schmitt, G. Ventro, F.R. Kona, Q.P. Dou, Dithiocarbamate-based coordination compounds as potent proteasome inhibitors in human cancer cells, Mini reviews in medicinal chemistry, 12 (2012) 1193-1201.

[50] S.G. Shian, Y.R. Kao, F.Y. Wu, C.W. Wu, Inhibition of invasion and angiogenesis by zincchelating agent disulfiram, Molecular pharmacology, 64 (2003) 1076-1084.

[51] M. Wehbe, M. Anantha, M. Shi, A.W. Leung, W.H. Dragowska, L. Sanche, M.B. Bally, Development and optimization of an injectable formulation of copper diethyldithiocarbamate, an active anticancer agent, Int J Nanomedicine, 12 (2017) 4129-4146.

[52] S.S. Sabharwal, P.T. Schumacker, Mitochondrial ROS in cancer: initiators, amplifiers or an Achilles' heel?, Nat Rev Cancer, 14 (2014) 709-721. 


\section{Figure captions}

Fig. 1: Effect of DSF, $\mathrm{Zn}(\mathrm{DDC})_{2}, \mathrm{Fe}(\mathrm{DDC})_{2}, \mathrm{Cu}(\mathrm{DDC})_{2}$ on Panc1 parental $(\mathrm{P})(\mathbf{A}$ and $\mathbf{B})$ and Panc1 CSCs (C and D) cell growth. Cells were seeded in 96-well plates and treated after 24 hours with increasing concentrations of DSF formulations for 24 hours (A and C) or 72 hours (B and D). Cell growth was determined using the resazurin cell viability assay. Values are the means \pm SEM of three independent experiments each performed in triplicate. Statistical analysis: DSF or Zn(DDC) 2 or $\mathrm{Fe}(\mathrm{DDC})_{2}$ versus $\mathrm{Cu}(\mathrm{DDC})_{2}, * \mathrm{p}<0.05$.

Fig. 2: DSC thermograms of pure DSPC, DSPC + mPEG-DSPE and DSPC+mPEG-DSPE+DSF.

Fig. 3: Cryo-TEM images of empty liposomes (A) and $\mathrm{Cu}(\mathrm{DDC})_{2}$ loaded liposomes (B-F).

Fig. 4: Effect of $\mathrm{Cu}(\mathrm{DDC})_{2}$ and of liposome formulations $\mathrm{LipoCu}(\mathrm{DDC})_{2}-5 \% \mathrm{PEG}, \mathrm{LipoCu}(\mathrm{DDC})_{2}-$ $5 \% \mathrm{HA}_{4800}, \quad \mathrm{LipoCu}(\mathrm{DDC})_{2}-5 \% \mathrm{HA}_{17000}, \quad \mathrm{LipoCu}(\mathrm{DDC})_{2}-2 \% \mathrm{PEG}-3 \% \mathrm{HA}_{4800}, \quad \mathrm{LipoCu}(\mathrm{DDC})_{2}-$ 2\%PEG-3\% HA 17000 on Panc1 parental (P) (A and B) and Panc1 CSCs (C and D) cell growth. Cells were seeded in 96-well plates and treated after 24 hours with increasing concentrations of $\mathrm{Cu}(\mathrm{DDC})_{2}$ formulations for 24 hours $(\mathbf{A}$ and $\mathbf{C}$ ) or 72 hours (B and $\mathbf{D})$. Cell growth was determined using the resazurin cell viability assay. Values are the means \pm SEM of three independent experiments each performed in triplicate. Statistical analysis: liposome formulations versus $\mathrm{Cu}(\mathrm{DDC})_{2}, * \mathrm{p}<0.05$.

Fig. 5: Effect of DSF, $\mathrm{Cu}(\mathrm{DDC})_{2}$, LipoCu(DDC) $)_{2}-5 \% \mathrm{PEG}$ and $\mathrm{LipoCu}(\mathrm{DDC})_{2}-2 \% \mathrm{PEG}-3 \% \mathrm{HA}_{17000}$ on Panc1 parental (P) and Panc1 CSCs cell growth. Cells were treated with $0.1 \mu \mathrm{M}$ of compounds for 24 hours (A) or 72 hours (B). Statistical analysis: CTRL versus treated, or as indicated in figure $* \mathrm{p}<0.05, * * \mathrm{p}<0.01, * * * \mathrm{p}<0.001$.

Fig. 6: Analyses of intracellular ROS production on Panc1 parental cells and Panc1 CSCs at the constitutive level (A) and after treatment with $\mathrm{LipoCu}(\mathrm{DDC})_{2}-2 \% \mathrm{PEG}-3 \% \mathrm{HA}_{17000}$ containing 0.1 $\mu \mathrm{M}$ of the active compound for 24 hours treatment (B). Effect of $5 \mathrm{mM} \mathrm{NAC}$ and/or $0.1 \mu \mathrm{M}$ LipoCu(DDC) $)_{2}$-2\%PEG-3\%HA 17000 on Panc1 parental and Panc1 CSC cell growth after 24 hours treatment $(\mathbf{C})$. Absolute glutathione quantification (arbitrary ion counts) in Panc1 cells (P; white histogram) and Panc1 CSCs (black histogram) (D). Values are presented as mean \pm SEM. Statistical analysis: $\mathrm{P}$ cells versus CSCs, or as indicated in figure $* \mathrm{p}<0.05, * * \mathrm{p}<0.01$.

Fig. 7: Effect of DSF, Cu(DDC) $)_{2}$, LipoCu(DDC $)_{2}-5 \%$ PEG and LipoCu(DDC $)_{2}-2 \%$ PEG-3\%HA 17000 on cell growth of primary PDAC cells $(12556, \mathrm{~A} 6 \mathrm{~L}, \mathrm{C} 75, \mathrm{C} 76, \mathrm{C102})$ cultured as first and second 
generation spheres. Cells were treated with $0.1 \mu \mathrm{M}$ compounds for 24 hours. Cell growth was determined using the resazurin cell viability assay. Values are the means \pm SEM of three independent experiments each performed in triplicate. Statistical analysis: CTRL versus treated, or as indicated in figure $* \mathrm{p}<0.05, * * \mathrm{p}<0.01, * * * \mathrm{p}<0.001$.

Fig. 8: Effect of DSF, $\mathrm{Cu}(\mathrm{DDC})_{2}$, $\mathrm{LipoCu}(\mathrm{DDC})_{2}-5 \% \mathrm{PEG}$ and $\mathrm{LipoCu}(\mathrm{DDC})_{2}-2 \% \mathrm{PEG}-3 \% \mathrm{HA}_{17000}$ on 12556, C75, C76, and C102 spheres formation capability. Cells were seeded in 24-well plates for first or second generation spheres and treated after 3 days with $0.1 \mu \mathrm{M}$ compounds for 4 days. Spheres number was determined through sphere formation assay performed by CASY Counter and reported as spheres of $40-80 \mu \mathrm{m}, 80-120 \mu \mathrm{m}$ and $>120 \mu \mathrm{m}$ of diameter. Statistical analysis: CTRL versus treated, or as indicated in figure $* \mathrm{p}<0.05, * * \mathrm{p}<0.01, * * * \mathrm{p}<0.001$. 